\title{
Study on Sub-National Government's Participation in International Regional Governance
}

\author{
Zhao Yonglun \\ School of Public Administration \\ Yunnan University of Finance and Economy \\ Kunming, China \\ (yy105788@163.com)
}

\begin{abstract}
As the globalization evolves, international governance system gradually displays diversified pattern, and a growing number of non-government subjects get involved in international governance and plays an increasingly important role. In regional international governance, sub-national subjects have strong points like grasping regional information in a more flexible and active way than the state subject, so it plays an irreplaceable role in international exchange. It will be of significance for the country to expand the diplomatic relation room, boost international understanding, and nourish more stable diplomatic environment if the sub-national entity plays a role in international regional governance, and establishes diversified foreign diplomatic systems.
\end{abstract}

Keywords-regional governance, sub-national government, international cooperation

\section{LiterATURE REVIEW}

Sub-national governments refer to governments of all levels under the central government, which exercise diplomatic functions not on behalf of the whole state, including local governments of all levels in unitary states, federal members and local governments of prefectures and provinces in federal states. After 1970s, the international exchange facilitated by globalization soars exponentially, the traditional international exchange dominated by sovereign states are overwhelmed, so wide room is provided for other non-national subjects to get involved in international activities. International actors of different levels and types go beyond national visions and boundaries, extend the scope of international governance to global areas, and form the global governance system with diversified participants, such as sovereign state, international organizations, non-government organizations and individual citizens. This has weakened the role of central government on behalf of the state to some extent, and the international exchange function held by the central government before is gradually delegated. Sub-national government, as a subject with special positions, plays an increasingly prominent role in international exchange, especially regional international exchange, and develops into important force for national governments to expand the foreign exchange.

There are quite many research fruits at home and abroad from study on participation of sub-national governments in international regional governance. Famous American futurist
Alvin Toffler thinks that in international pattern change in future, there are always "some forces try to transfer political powers from nationality country to the areas and groups of the country, and some other forces try to transfer the national power to trans-national institutions and organizations"'[1]. Based on research on sub-national government of Australia, Dollery, Crase, Johnson, etc. (2006) point out that the functions of sub-national government are expanded from services, infrastructure construction, social welfare, etc. to wider economic areas, and undertake the responsibility to promote local economy development. After conducting study on the role of British sub-national governments,[2] Chandler thinks that the significance of activities of sub-national government including international activities is not to provide services for residents in the area, but moreover promote the process of democratization, and advance social process of democratization and liberalization.[3] Johnson, another American scholar thinks that as the function of the central government is expanded, its functions will inevitably go beyond its capacity, so the supplementation of sub-national government is needed. Hence sub-national governments own some non-excluding rights to the central government (Johnson, 1978).[4] The study suggests it is a trend for sub-national government to take part in international governance, and its role cannot be replaced.

Chinese scholars also carry out much research on participation of sub-national government in international governance. Huang Jianwen (2006) illustrates it is inevitable for sub-national governments to get involved in international cooperation from the global governance respect, and he thinks that global governance structure is a governance framework of multi-layers, and it is a trend to transfer national administrative functions lower and out to sub-national institutions.[5] $\mathrm{Li}$

[1] Alvin Toffler, the Third Wave, translated by Zhu Zhimiao. Beijing: SDX Joint Publishing Company, 1983,383

[2] Dollery, B., Crase,L., Johnson, A. Australian Local Government Economics. Sydney: University of New South Wales Press Ltd. 2006.

[3] Chandler, J. A. Local Government Today. 3rd ed. Manchester: Manchester University Press. 2001.

[4] Johnson, P. R. Provincial International Activities. International Journal. 33, 359 .

[5] Li Zhengang. On Building Transnational Local Government Relations, Journal of Guangxi University for Nationalities (philosophy and social science). 2006 (1), 167-174 
Zhengang (2006) thinks that accelerated globalization promotes trans-national exchange of local governments into the new trend of international relation development, and this is helpful to boost local competitiveness, realize supplementary interests and resources, and cut down trading costs for local development. After studying Sino-US exchange course,[6] Ba Cuicui (2014) holds the opinion that under the increasing globalization background, Driven by the appealing Chinese market and local economy growth and employment requirements, American sub-national governments get involved in Sino-US international cooperation more frequently. By visiting China, establishing friendly provinces, states and cities, setting up China-oriented agencies and other channels, American sub-national governments have developed positive exchange and cooperation with Chinese local governments, and accomplished remarkable results. After studying the role of sub-national governments in international cooperation in his doctoral thesis,[7] Jiang Changxin (2011) thinks that the international cooperation of sub-national government is closely related to the country's system, structure, culture and history, and decides the role of the sub-national government on the international arena and the depth and width of international cooperation.

\section{Characteristics OF Sub-National GOVERNMENT'S PARTICIPATION IN INTERNATIONAL COOPERATION}

Compared with the central government on behalf of the state, sub-national governments don't exercise national sovereignty, they are not subjects inherently exercising diplomatic functions, and they are under the control of the central government in activities concerning foreign affairs, which on one hand restricts the international cooperation room and depth, but on the other hand gets free from restrictions like ideology, political system, international treaty, etc. Therefore, sub-national governments not on behalf of sovereignty responsibilities boast advantages, such as flexible and widespread choices in international cooperation. Generally speaking, sub-national governments have characteristics as follows when getting involved in international governance.

Firstly There are multiple dimensions and levels for subnational governments to take part in international governance. Firstly seen from the areas of international governance involved, the content is more extensive. Political, economic, social, environmental and other areas are all likely to be the content for sub-national governments to take part in international cooperation and governance, and the key areas are economic areas such as trade and investment, and social development fields like ecological environment, human resources, etc.; secondly seen from the subject structures involved in international governance, sub-national governments of different levels have different roles, and their international activities' depth and width are closely related to the levels of sub-national government; thirdly theoretically

[6] Ba Cuicui. Outlook on Motivation, Channels and Prospect of Exchange between American Sub-National Governments and China. File[J].2014(7).

[7] Jiang Changxin. Research on Issues concerning Sub-National

Government's Participation in International Cooperation-Take Jilin Province Government for Example. Doctorate thesis of Jilin University (D). 2011(6) speaking, sub-national governments of all levels are likely to participate in international governance, but the ones of higher levels are more active than those of lower levels.

Secondly it is incomplete for sub-national governments to take part in international governance. The reasons are as follows: firstly sub-national governments could only develop international cooperation and governance within a certain scope, and generally they don't own complete international legal status, and their international cooperation areas will be restricted to some extent. For example, in some areas in need of national sovereignty, sub-national governments are unable or unlikely to take part in; secondly the levels for sub-national governments to get involved in international cooperation and governance are restricted, sub-national governments are only able to reach international cooperation agreements within their functional scope and power, so the governance and cooperation is limited.

Thirdly sub-national governments are relatively independent to get involved in international cooperation and governance. Although theoretically speaking, the diplomatic functions of one country are exercised by the central government, and local governments don't own independent diplomatic rights, it is impossible for the central government to control all foreign affairs, and moreover, diplomacy is diversified and has multiple levels, so sub-national governments are able to implement certain independent diplomatic activities in some areas. For example, on one hand sub-national governments could choose equal international cooperation partners in a relatively independent way according to their conditions, economy \& trade with relevant countries, geographical relations, etc., and they are independent of central governments in a certain scope to develop bilateral or multipartite cooperation; on the other hand, sub-national governments decide international cooperation content, projects, key points and cooperation ways within their responsibility scope and on the foundation of not violating general strategies and principles of the central government.

\section{AdVANTAGES AND Limitations FOR SUB-NATIONAL GOVERNMENT TO GET INVOLVED IN INTERNATIONAL REGIONAL GOVERNANCE}

\section{A. Advantage for Sub-National Governments to Take Part in International Regional Governance}

Generally speaking, compared with diplomatic activities of central governments, sub-national governments own the following advantages in participating in international regional governance courses:

1) Sub-national governments are more flexible in participating in international governance activities. Generally speaking, the central government on behalf of the state always adopt relatively standard ways in international cooperation, and fix the partnership between countries in international treaties, conventions, etc., which are quite steady, so central governments are more prudent in governance, cooperation, ways, projects, etc., attach importance to long-term strategies, and ignore specific mattes, which means less flexibility. 
Cooperation among sub-national governments are pretty flexible, and sub-national countries may adopt different ways, choose relatively specific content, and have comparatively simple procedures and long or short cooperation durations.

2) As sub-national governments' international cooperation is flexible and unrestricted, and possible loss resulted from failure is not much, it serves as the experimental way to explore international exchange mechanism innovation and breakthrough. Especially in some comparatively sensitive areas and specific matters, cooperation of sub-national governments is the pioneer and exploring means for international cooperation, an effective way to break diplomatic stalemate, and it could create good diplomatic environment for in-depth cooperation between countries.

3) International cooperation between sub-national governments is of less political sensitivity, cooperation is focused on projects not quite related to political areas, such as economy, culture, and social development, and it is not quite much affected by international political relations, not probable of causing international political and social reactions. Not much international resistance is encountered in cooperation and governance, and it is relatively possible to get difficult and successful cooperation and governance. The cooperation matters are relatively specific, not involving policy adjustment, so consensus is easily reached.

\section{B. Limitations for Sub-National Governments to Take Part in International Cooperation}

As sub-national governments cannot represent national sovereignty to develop foreign cooperation and governance, the maximum restriction lies in restricted international regional governance scope.

Firstly, the areas for sub-national governments to take part in international regional cooperation and governance are nontraditional safety areas, the key area is economic cooperation, and main areas also include social development areas like ecological protection, cultural exchange, education and health. However, sub-national governments are difficult to get involved in cooperation and governance concerning the whole national security and strategies.

Secondly, levels and authority of sub-national government cooperation are restricted by central governments to a large extent. On one hand, sub-national governments cannot go against strategic intentions and principles of central governments in developing international regional governance and cooperation; otherwise, such international regional governance and cooperation will be directly intervened by the central government, and support from central governments will be impossible. Secondly in international cooperation of major projects involving national interests, the final cooperation is always up to participation and recognition of central governments; thirdly the scope for sub-national governments to choose international cooperation partners depends on the achievements from diplomacy accomplished by the central government and international environment shaped.
Thirdly, sub-national governments have many risks in taking part in international governance and cooperation. Firstly sub-national government is not a complete subject of international law, and its international behaviors cannot be protected by international legal systems; secondly sub-national government subjects have generally weak capability in resisting risks, and they are difficult in resisting risks caused by complicated international environment; thirdly when national relations have changed, in order to protect integral interests of a country, the central government will sacrifice interests of subnational governments in participating in international governance.

\section{WAYS FOR SUB-NATIONAL GOVERNMENTS TO TAKE PART IN INTERNATIONAL REGIONAL GOVERNANCE}

Firstly, in the international level, sub-national governments should fully learn their internal development requirements, grasp international governance rules and systems, carry out practice to shape interactions and participations, try to combine action orientations with main topics of the international society, and improve capabilities and successful rates of participating in international governance.

Secondly in the national level, sub-national governments should comprehensively understand the whole country's diplomatic strategic intentions, align international regional governance actions with national strategies, actively seek for support from central government, and meanwhile, work as a pioneer to realize nationally strategic objectives based on its diplomatic efforts, and create good environment for the state and own international activities.

Lastly, sub-national governments should strengthen coordination and distribution of responsibilities of peers in participating in international regional governance, establish uniform organizational coordination and supervisory mechanism, prevent vicious competition, safeguard overall interest of the state, and beef up overall strengths to participate in international governance.

\section{REFERENCES}

[1] Alvin Toffler, the Third Wave, translated by Zhu Zhimiao. Beijing: SDX Joint Publishing Company, 1983,383

[2] Dollery, B., Crase,L., Johnson, A. Australian Local Government Economics. Sydney : University of New South Wales Press Ltd. 2006.

[3] Chandler, J. A. Local Government Today. 3rd ed. Manchester: Manchester University Press. 2001.

[4] Johnson, P. R. Provincial International Activities. International Journal. $33,359$.

[5] Huang Jianwen, Sub-National Governance and urban Government Governance Innovation. Wuhan: Journal of Jianghan University(Social Science). 2006 (4), 29-32.

[6] Li Zhengang. On Building Transnational Local Government Relations, Journal of Guangxi University for Nationalities (philosophy and social science). 2006 (1), 167-174

[7] Ba Cuicui. Outlook on Motivation, Channels and Prospect of Exchange between American Sub-National Governments and China. File[J].2014(7).

[8] Jiang Changxin. Research on Issues concerning Sub-National Government's Participation in International Cooperation-Take Jilin 
Province Government for Example. Doctorate thesis of Jilin University (D). 2011(6)
[9] Sun Ying, Analysis of Diplomatic Status of Sub-National Government, Modern Property, Modern Economy 2015(2). 